\title{
Myopathic Form of Very-Long Chain Acyl-CoA Dehydrogenase Deficiency: Evidence for Temperature-Sensitive Mild Mutations in Both Mutant Alleles in a Japanese Girl
}

\author{
TOSHIYUKI FUKAO, HIROH WATANABE, KENJI E. ORII, YUKITOSHI TAKAHASHI, \\ AKIKO HIRANO, TOMIO KONDO, SEIJI YAMAGUCHI, TOSHIFUMI AOYAMA, AND \\ NAOMI KONDO \\ Department of Pediatrics, Gifu University School of Medicine, Gifu 500-8075, Japan [T.F., H.W., K.E.O, \\ Y.T., A.H., N.K.]; Department of Pediatrics, Ogaki Municipal Hospital, Ogaki, Gifu 503-8502, Japan \\ [T.K.]; Department of Pediatrics, Shimane Medical University, Izumo, Shimane 693-8501, Japan [S.Y.]; \\ and Department of Aging Biochemistry, Shinshu University School of Medicine, Matsumoto, Nagano \\ 390-8621, Japan [T.A.]
}

\begin{abstract}
ABST
In a 14-year-old Japanese girl, manifested recurrent myalgia
with elevated serum creatine kinase after moderate exercise
became evident, and she was diagnosed as having a myopathic
form of very-long chain acyl-CoA dehydrogenase deficiency.
Her first clinical symptom of the disease was evident when she
was 6 y of age. She had never had hypoglycemic attacks, and
hepatomegaly and cardiomyopathy were absent. The diagnosis
was suspected on the basis of the urinary organic acid profile
after a $36-$-h fast, long-chain fatty acid-loading test, and the blood
acylcarnitine profile. Acyl-CoA dehydrogenase activity with
palmitoyl-CoA as a substrate was severely decreased in her
fibroblasts, and the amount of very-long chain acyl-CoA dehy-
drogenase protein was reduced. She was a compound heterozy-
gote of A416T from her father and R450H from her mother.
Transient expression of mutant A416T cDNA retained a signif-
icant residual acyl-CoA dehydrogenase activity of $10^{\circ} \%$ and $20 \%$
normal at $37^{\circ} \mathrm{C}$ and $30^{\circ} \mathrm{C}$, respectively. Specific activity of
A416T mutant protein was calculated to be one fifth that of
\end{abstract}
VLCAD(EC 1.3.99.13; HUGO symbol, ACADVL) belongs to the $\beta$-oxidation system of long-chain fatty acids together with mitochondrial enoyl-CoA hydratase/3-hydroxyacyl-CoA dehydrogenase/3-ketoacyl-CoA thiolase trifunctional protein $(1,2)$.The clinical phenotype of VLCAD deficiency (MIM\# 201475) was first divided into two different forms (3); a severe presentation characterized by early onset of symptoms, with hypertrophic cardiomyopathy and a high incidence of death,

Received April 3, 2000; accepted September 8, 2000

Correspondence to Toshiyuki Fukao, M.D., Ph.D., Department of Pediatrics, Gifu University School of Medicine, 40 Tsukasa-machi, Gifu 500-8075, Japan.

Supported in part by grants for the promotion of science research from The Ministry of Education, Science, Sports, and Culture of Japan and by ONO Medical Research Foundation. control. In the case of $\mathrm{R} 450 \mathrm{H}$ mutant expression, a low residual acyl-CoA dehydrogenase activity of $5 \%$ normal was detected at $30^{\circ} \mathrm{C}$ although significant activity was absent at $37^{\circ} \mathrm{C}$. The $\mathrm{R} 450 \mathrm{H}$ protein was not detected at $37^{\circ} \mathrm{C}$ but was clearly detected at one fourth the normal amount at $30^{\circ} \mathrm{C}$. These results indicate that both mutations were temperature-sensitive mild mutations, the result being the mildest phenotype of very-long chain acylCoA dehydrogenase deficiency. (Pediatr Res 49: 227-231, 2001)
CK, creatine kinase
CT, cytosolic acetoacetyl-CoA thiolase
RT-PCR, reverse transcription PCR
VLCAD, very-long chain acyl-CoA dehydrogenase
C16-DH activity, acyl-CoA dehydrogenase activity with
palmitoyl-CoA as a substrate

Abbreviations: and a milder form with a late onset with Reye-like disease, hypoketotic hypoglycemia, no cardiac involvement, and a more favorable outcome. Later occurrences in adolescents and adults have been reported, with the absence of hypoglycemia and cardiomyopathy but with episodes of rhabdomyolysis and myoglobinuria, usually triggered by exercise or fasting (4-7). Hence VLCAD deficiency can be separated into three clinical phenotypes (8).

Gene mutations in VLCAD deficiency have been reported, with a wide spectrum (8-14). Andresen et al. (8) suggested a clear correlation of genotype with disease phenotype in VLCAD deficiency, from data on 58 independent mutations in 55 unrelated patients. They reported that most patients with the severe childhood form had two null mutations and that most 
patients with the mild childhood form or adult form have missense mutations that might result in residual enzyme activity; they found that two missense mutations retained residual VLCAD activities.

There have been a number of reported cases of VLCAD deficiency, patients who presented with recurrent myoglobinuria (4-6), including those of childhood onset (7). We describe herein a case of a myopathic form of VLCAD deficiency in a Japanese girl who presented with the disease at $6 \mathrm{y}$ of age. Molecular analyses at the protein and DNA level revealed that the mutations retained VLCAD activity and that there was temperature sensitivity.

\section{METHODS}

Case presentation. A 14-year-old Japanese girl was admitted to Gifu University Hospital for evaluation of recurrent myalgia with elevated CK. Informed consent was obtained from the patient and her parents to perform clinical and molecular studies, and these studies were approved by the review board of Gifu University School of Medicine. She was born to nonconsanguineous parents, at full term, weighing $3360 \mathrm{~g}$. She had been well until age $6 \mathrm{y}$ when she looked pale and felt fatigue after school. At that time, an elevated serum CK was detected at Ogaki Municipal Hospital. The symptoms completely diminished 1 wk later with normalization of the CK level. At age $8 \mathrm{y}$, after going for a walk, she again developed myalgia with elevated CK. Muscle biopsy revealed no abnormal histologic findings. She had experienced similar episodes several times a year. Urinary organic acid analysis during myalgia crises repeatedly showed no remarkable findings. She had no documented hypoglycemic episodes in childhood. She had been followed at Ogaki Municipal Hospital as a case of probable myopathy of unknown cause for more than $6 \mathrm{y}$.

At the time of admission (14 $\mathrm{y}$ of age), she was $161.1 \mathrm{~cm}$ tall and weighed $44.8 \mathrm{~kg}$. Hepatomegaly was not present. Laboratory data after a overnight fast were within normal ranges, as follows: aspartate aminotransferase $17 \mathrm{IU} / \mathrm{L}$ (range, 10-40 $\mathrm{IU} / \mathrm{L}$ ); alanine aminotransferase, $12 \mathrm{IU} / \mathrm{L}$ (range, 5-40 IU/L); lactate dehydrogenase $290 \mathrm{IU} / \mathrm{L}$ (range, 230-460 IU/L); CK $39 \mathrm{IU} / \mathrm{L}$ (range, 32-180 IU/L); Uric acid, $0.19 \mathrm{mM}$ (range, 0.15-0.32 mM); glucose, 5.4 mM (range, 3.9-6.1 mM); myoglobin, $<3.5 \mu \mathrm{M}$; acetoacetate, $0.02 \mathrm{mM}(<0.055 \mathrm{mM})$; 3-hydroxybutyrate, $0.051 \mathrm{mM}(<0.085 \mathrm{mM})$; FFA, $0.37 \mathrm{mM}$ (range, 0.14-0.85 mM); and lactic acid, $1.1 \mathrm{mM}$ (range, $0.37-1.65 \mathrm{mM}$ ). Urinary organic acid analysis showed no remarkable findings, and the echocardiogram revealed no cardiomyopathy. A 36-h fasting period was carefully monitored, both clinically and metabolically, as prolonged fasting in children with fatty acid oxidation defects poses a risk. During the 36-h fast (Fig. 1), hypoglycemia did not occur. Serum levels of ketone bodies were very low compared with the level of FFA (the ratio of FFA to ketone bodies $>6$ at 25 -h fasting). She complained of myalgia after a 13-h fast, and the level of CK was $>2000 \mathrm{IU} / \mathrm{L}$; the level exceeded $6000 \mathrm{IU} / \mathrm{L}$ after a 36 h-fast. Her urine was then positive for myoglobin. Organic acid analysis of urine at end of the fast revealed hypoketotic dicarboxylic aciduria in which adipic acid $(1300.3 \mu \mathrm{mol} / \mathrm{mol}$ cre-

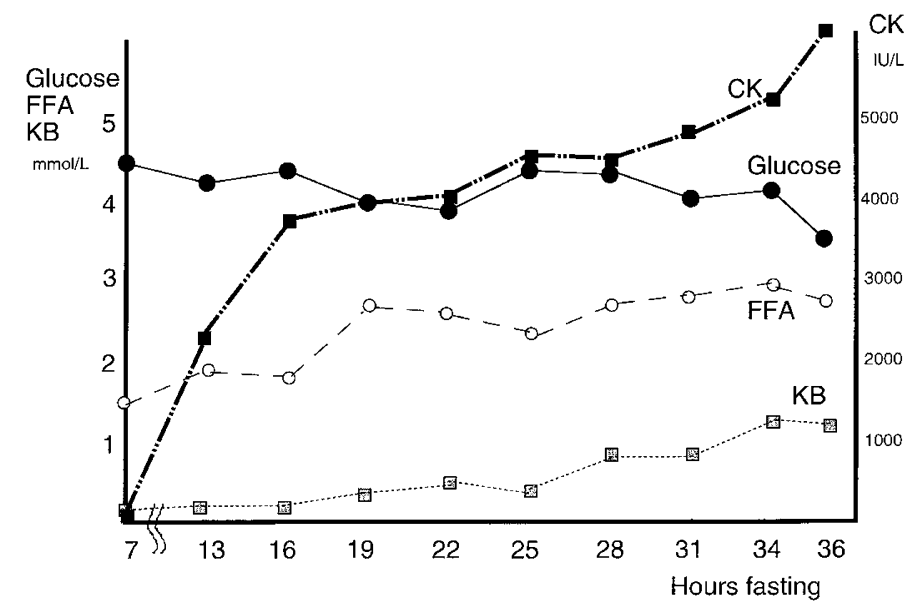

Fig. 1. Results of a 36-h fast. $K B$, total ketone body (acetoacetate and 3-hydroxybutyrate).

atinine, range $1.6-16.5 \mu \mathrm{mol} / \mathrm{mol})$, suberic acid $(212.3 \mu \mathrm{mol} /$ $\mathrm{mol}$, range, $0.3-8.6 \mu \mathrm{mol} / \mathrm{mol})$, sebacic acid $(108.9 \mu \mathrm{mol} / \mathrm{mol}$, range, $0.3-5.0 \mu \mathrm{mol} / \mathrm{mol})$, dodecanedioic acid $(12.8 \mu \mathrm{mol} /$ mol, not detected) and their 3-hydroxycompounds were evident. Long-chain fatty acid $(1.25 \mathrm{~g} / \mathrm{kg})$ and medium-chain fatty acid $(1.25 \mathrm{~g} / \mathrm{kg})$ loading tests after a $14-\mathrm{h}$ fast were then performed. Serum levels of ketone bodies were elevated in medium-chain fatty acid loading, but not so in long-chain fatty acid loading. Acyl-carnitine analysis of samples during longchain fatty acid loading, a time when she was well, and during a myalgia crisis were performed by Dr. N. Terada (Department of Pediatrics, Kyoto Prefectural University of Medicine). $\mathrm{C}_{14: 1}$ acylcarnitine was elevated under all these conditions, findings indicating a defect of long-chain fatty acid. The final diagnosis was VLCAD deficiency, as determined by enzyme assay, and she was discharged.

She sometimes complained of myalgia, and CK levels were elevated (up to 10,000 IU/L) after exercise or emotional stress. Intravenous glucose was prescribed in such cases. We recommended avoidance of a high-fat diet. Cardiomyopathy and hypoglycemia were absent. She is now 17 years old, and her intelligence is normal.

Fibroblasts and peripheral blood mononuclear cells. Fibroblasts from the patient were cultured in Eagle's minimal essential medium containing 10\% FCS. Peripheral blood mononuclear cells were purified from the parents' heparinized blood samples by Ficoll gradient centrifugation.

Assay for acyl-CoA dehydrogenase activity. Fibroblast pellets were preserved in $50 \mathrm{mM}$ sodium phosphate $(\mathrm{pH} \mathrm{8.0)}$, $0.1 \%$ Triton X-100, $0.2 \mathrm{M}$ sodium chloride. After sonication and incubation for $30 \mathrm{~min}$ on ice, the supernatant was obtained by centrifugation at $10,000 \times g$ for $10 \mathrm{~min}$. Acyl-CoA dehydrogenase assay was performed using the dye-reduction method described by Verity and Turnbull (15), but with some modification (13).

Immunoblot analysis. Fibroblast extract $(30 \mu \mathrm{g})$ was applied to a $10 \%$ SDS-PAGE. Immunoblot analysis was performed using a ProtoBlot Western Blot AP System (Promega, Madison, WI, U.S.A.). Anti-human VLCAD antibody (16) and anti-human CT antibody (17) were used as the first antibody. 
$\boldsymbol{R} \boldsymbol{T}-\boldsymbol{P} \boldsymbol{C R}$. Total RNA was extracted from fibroblasts, using an ISOGEN kit (Nippon Gene, Tokyo, Japan). RT-PCR was performed as described (18). Briefly, first-strand cDNA synthesis was performed with VLCAD-specific antisense primer $\left(5^{\prime}{ }^{2010}\right.$ GAGGGAAGGCACATAACTGG $\left.{ }^{1991}-3^{\prime}\right)$. Two cDNA fragments were amplified, using the following primer sets: fragment 1 , sense primer $\left(5^{\prime}-{ }^{22} \mathrm{CGGCGCCCGGAGAGAT-}\right.$ $\left.\mathrm{TCGG}^{-3}-3^{\prime}\right)$ and antisense primer $\left(5^{\prime}-{ }^{1062}\right.$ GCCTCTCATGGTACCTGCCA $\left.{ }^{1043}-3^{\prime}\right)$; fragment 2 , sense primer $\left(5^{\prime}\right.$ ${ }^{814}$ ACAGGAGCCGTGAAGGAGAA $\left.^{833}-3^{\prime}\right)$ and antisense primer (5' ${ }^{\prime}{ }^{1988}$ CAGGCCCTGGCCGGGAGTAT $\left.{ }^{1969}-3^{\prime}\right)$. Amplified fragments were subcloned into pMOSblue $\mathrm{T}$ vector (Amersham Pharmacia Biotech. Buckinghamshire, U.K.), sequenced using PRISM Ready Reaction Terminator Cycle Sequencing kit (Perkin-Elmer Corp., Foster City, CA, U.S.A.), and analyzed on an ABI 373A DNA sequencer (Perkin-Elmer Corp.).

Restriction enzyme assay at the gene level. Genomic DNA was purified using a Sepa Gene kit (Sanko Junyaku, Tokyo, Japan). Restriction enzyme assay was performed to detect mutations at the gene level. We first amplified a genomic fragment from intron 11 to exon 14 using VLCAD In $11 \mathrm{~B}$ primer located in intron 11 (5'-GTGATGAGGCCAAGTCTGAC- $\left.3^{\prime}\right)$ and an antisense primer VLCAD148 located in exon $14\left(5^{\prime}{ }^{1391}\right.$ GTCCCTCAAAGATCCGGAA $\left.{ }^{1372}-3^{\prime}\right)$. Forty cycles of amplification were run $\left(94^{\circ} \mathrm{C}, 1 \mathrm{~min} ; 54^{\circ} \mathrm{C}, 2 \mathrm{~min}\right.$; $\left.72^{\circ} \mathrm{C}, 3 \mathrm{~min}\right)$. A second PCR $\left(25\right.$ cycles of $94^{\circ} \mathrm{C}, 1 \mathrm{~min} ; 37^{\circ} \mathrm{C}$, $2 \mathrm{~min} ; 72^{\circ} \mathrm{C}, 2 \mathrm{~min}$ ) was performed using an aliquot of the first PCR solution to detect mutations in a restriction enzyme assay, followed by electrophoresis on a $5 \%$ polyacrylamide gel, as follows:

For detection of $1246 \mathrm{G}$ to A (A 416T): Amplification with a mismatch sense primer mismatch $1\left(5^{\prime}-{ }^{1225}\right.$ ACGGACTTCCAGATAGTGGCC $\left.{ }^{1245}-3^{\prime}\right)$ and VLCAD148 primer was followed by BalI digestion. A fragment with the A416T mutation was digested with BalI from 340 bp into 321 and 19 bp.

For the detection of $1349 \mathrm{G}$ to A (R450H): Amplification with the mismatch 1 primer and a mismatch antisense primer mismatch $2\left(5^{\prime}{ }^{-1371}\right.$ GATGCGAAGATCTCGGAGCGCA ${ }^{1350}$ $3^{\prime}$ ), followed by NspI. A fragment without R450H was digested into $60 \mathrm{bp}$ and $270 \mathrm{bp}$, and a fragment with $\mathrm{R} 450 \mathrm{H}$ mutation into $60 \mathrm{bp}, 250 \mathrm{bp}$, and $20 \mathrm{bp}$.

Transient expression of normal and mutant cDNAs. As recipient cells, we prepared SV40-transformed fibroblasts from a VLCAD-null patient who was a homozygote of S22X mutation (18). Mutant VLCAD cDNAs were constructed from normal VLCAD cDNA by in vitro mutagenesis using QuickChange Site-Directed Mutagenesis Kits (Stratagene, La Jolla, CA, U.S.A.), according to manufacturer's instruction. A eukaryote expression vector, pCAGGS, was kindly provided by Dr. J. Miyazaki (19). Transfection protocol using Lipofectin (Life Technologies, Rockville, MD, U.S.A.) was the same as described (18). Briefly, $4 \mu \mathrm{g}$ of a VLCAD expression vector and $1 \mu \mathrm{g}$ of an expression vector for human CT were cotransfected into $5 \times 10^{5}$ cells. After a 72-h incubation period at $37^{\circ} \mathrm{C}$ or $30^{\circ} \mathrm{C}$, the cells were harvested and assayed for $\mathrm{C} 16-\mathrm{DH}$ activity. Acetoacetyl-CoA thiolase activity was assayed, as described (17).

\section{RESULTS}

Enzyme activity and immunoblot analysis. Acyl-CoA dehydrogenase activity with octanoyl-CoA as a substrate in fibroblasts from the patient $(2.6 \mathrm{nmol} / \mathrm{min} / \mathrm{mg}$ protein) was almost the same level as in a control $(n=6,3.3 \pm 1.0$ $\mathrm{nmol} / \mathrm{min} / \mathrm{mg}$ ); however, C16-DH activity of the fibroblasts from the patient $(0.16 \mathrm{nmol} / \mathrm{min} / \mathrm{mg})$ was decreased to $<10 \%$ of the control ( $n=6,2.3 \pm 0.5 \mathrm{nmol} / \mathrm{min} / \mathrm{mg})$, thus confirming that the patient had VLCAD deficiency.

VLCAD polypeptide was clearly identified as a $66-\mathrm{kD}$ band in control fibroblasts when $30 \mu \mathrm{g}$ of protein was applied. Fibroblasts from our patient had apparent VLCAD protein with a 50\% lesser amount than controls and the same mobility as controls. CT polypeptide was in an amount similar to that in controls (data not shown).

Gene mutations. When we sequenced clones of the cDNA fragment 2, either ${ }^{1246} \mathrm{G} \rightarrow \mathrm{A}(\mathrm{A} 416 \mathrm{~T})$ or ${ }^{1349} \mathrm{G} \rightarrow \mathrm{A}(\mathrm{R} 450 \mathrm{H})$ was detected. Amino acid residues are numbered with the initiator methionine being 1 . No other mutation was detected in the cDNA fragments. We also sequenced genomic fragments spanning from intron 11 to exon 14, including both mutation sites, and confirmed that either of these mutations was present in the cloned fragments. Restriction enzyme assays at the gene level revealed that A416T (in exon 12) was derived from her father and $\mathrm{R} 450 \mathrm{H}$ (in exon 14) from her mother (Fig. 2).

Transient expression of mutant cDNAs. VLCAD polypeptide and $\mathrm{C} 16-\mathrm{DH}$ activity were investigated in transient expression of the normal and mutant VLCAD cDNAs at 37 and $30^{\circ} \mathrm{C}$ (Fig. 3). Figure $3 A$ shows $\mathrm{C} 16-\mathrm{DH}$ activities relative to those in the cells transfected with normal VLCAD cDNA. We cotransfected the CT cDNA, and each transfection gave similar levels of acetoacetyl-CoA thiolase activity and CT protein in immu-

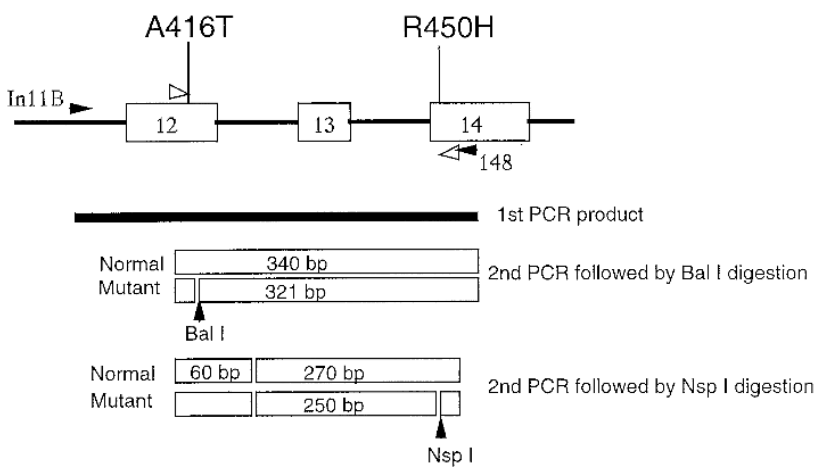

a) A416 $\mathrm{T}$ detection

b) $\mathrm{R} 450 \mathrm{H}$ detection

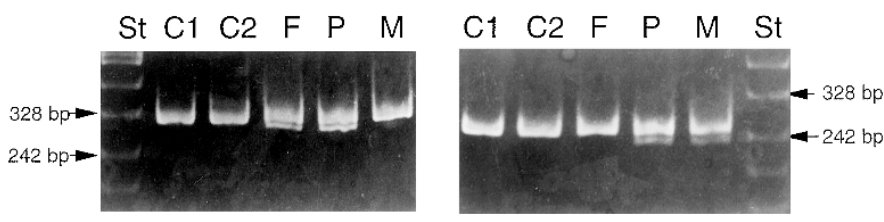

Fig. 2. Restriction enzyme assays at the genomic level. Top, schematic diagrams of the assays. Black arrowheads indicate positions for primers used in the first and second PCRs. White triangles indicate mismatched primers used in the second PCRs. Bottom, PAGE of restriction enzyme fragments. C1 and $C 2$ indicate controls. $F, P$, and $M$ indicate the father, the patient, and the mother, respectively. $a$, detection of A416T mutation. $b$, detection of $\mathrm{R} 450 \mathrm{H}$. 
(A)

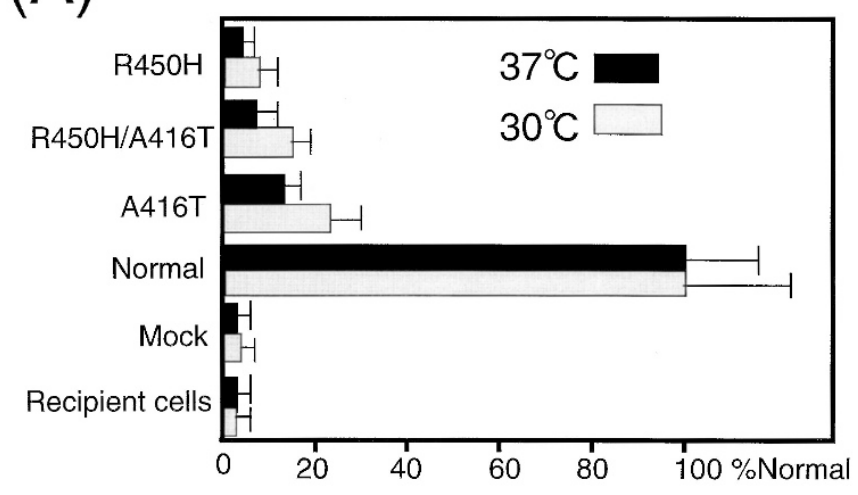

(B)
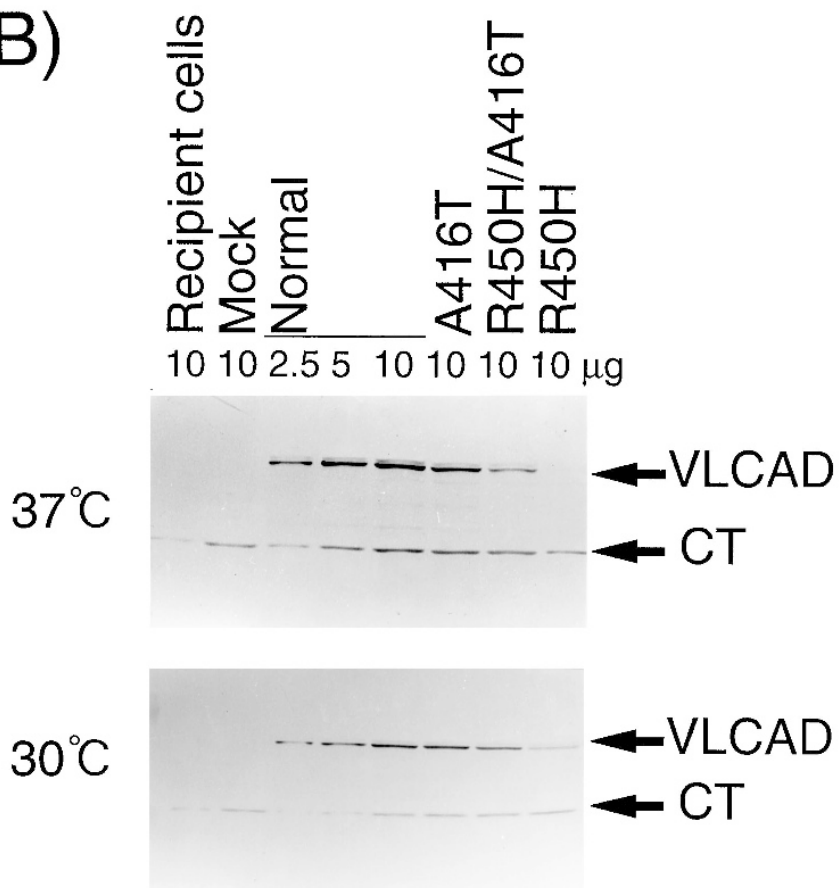

Fig. 3. Transient expression analysis. An expression vector for normal or one of the mutant VLCAD cDNAs was transfected into SV40-transformed VLCAD-deficient fibroblasts, together with an expression vector for human $\mathrm{CT}$, and incubated at 37 or $30^{\circ} \mathrm{C}$ for $72 \mathrm{~h}$. Enzyme assay was performed at $30^{\circ} \mathrm{C}$. Mock indicates transfection of an expression vector with no cDNA insertion instead of the VLCAD expression vector. R450H/A416T means cotransfection of $2 \mu \mathrm{g}$ each of $\mathrm{R} 450 \mathrm{H}$ and A416T expression vectors. $A$, C16-DH activities relative to those in cells transfected with normal VLCAD cDNA are shown. Average relative activities and SD of three independent experiments are shown. C16-DH activities in cells transfected with the normal cDNA were $4.6 \pm 1.0$ and $3.8 \pm 0.7 \mathrm{nmol} / \mathrm{min} / \mathrm{mg}$ protein in 37 and $30^{\circ} \mathrm{C}$, respectively. $B$, immunoblot analysis using a mixture of anti-human VLCAD antibody and anti-human CT antibody as the first antibody.

noblots, confirming that transfection efficiency is similar among each transfection. Mock cDNA transfection (lanes mock) produced neither VLCAD peptide nor C16-DH activity, compared with the recipient cells. On the other hand, normal VLCAD cDNA expression at 37 and $30^{\circ} \mathrm{C}$ resulted in apparent increases of VLCAD polypeptides and C16-DH activities (lanes normal). Expression of the A416T mutant cDNA at $37^{\circ} \mathrm{C}$ showed residual $\mathrm{C} 16-\mathrm{DH}$ activity $(10 \%$ normal) with a decreased amount of protein (about 50\% normal). In case of $30^{\circ} \mathrm{C}$ expression, the $\mathrm{C} 16-\mathrm{DH}$ activity and amount of mutant protein were increased to $20 \%$ of the normal and almost the same level as normal, respectively. In cases of expression of the $\mathrm{R} 450 \mathrm{H}$ mutant cDNA, no significant residual activity was detected at $37^{\circ} \mathrm{C}$, but a low residual $\mathrm{C} 16-\mathrm{DH}$ activity (about $5 \%$ control) was detected at $30^{\circ} \mathrm{C}$. VLCAD protein was not detected at $37^{\circ} \mathrm{C}$ but was clearly detected with one fourth the normal amount at $30^{\circ} \mathrm{C}$. Residual $\mathrm{C} 16-\mathrm{DH}$ activities and the amounts of VLCAD protein in coexpression of $\mathrm{R} 450 \mathrm{H}$ and A416T were almost mean values between those of separate expressions at both 37 and $30^{\circ} \mathrm{C}$.

\section{DISCUSSION}

We confirmed that a 14-year-old Japanese girl with recurrent attacks of myalgia with elevated CK was VLCAD deficient at the molecular level. Hypoglycemic attacks and cardiomyopathy never occurred. According to Andresen et al. (8), this patient could be classified as an adult form, the mildest type of VLCAD deficiency. Some patients with this form may have clinical onsets in childhood, as did our patient (7). We hence use the term an episodic, isolated myopathic form instead of adult form in the current report.

Our expression system of mutant cDNAs differed from that in previous reports $(9,13)$. To reduce intrinsic VLCAD activity, we used SV40-transformed fibroblasts derived from a VLCAD-deficient patient with a homozygous S22X mutation (18); hence interaction between intrinsic S22X mutant protein and an expressed mutant protein was expected to be nil. As shown in Figure 3, the basal C16-DH activity was extremely low, and VLCAD protein was not detected in immunoblots. We also cotransfected human CT cDNA to monitor transfection efficiency. These approaches facilitated evaluation of both residual VLCAD activity and the amount of mutant protein.

Our patient is a compound heterozygote of A416T and $\mathrm{R} 450 \mathrm{H}$ mutations. Smelt et al. (6) identified two missense mutations, R450H and G441D, in an adult form of VLCAD deficiency. During preparation of this manuscript, Merinero et al. (20) reported sibling cases with adolescent myopathic form of VLCAD deficiency with $\mathrm{N} 405 \mathrm{H}$ and $\mathrm{R} 450 \mathrm{H}$, hence R450H is in common with data on our patient. However, their reports did not include expression analysis of these mutations. When amino acid sequences of seven human acyl-CoA dehydrogenases were aligned to achieve maximum homologies, all acylCoA dehydrogenases had a positive charge (either lysine or arginine) at the homologous residue of R450 in VLCAD, thus indicating its importance (12). Because $\mathrm{R} 450 \mathrm{H}$ is a conservative change, and some residual dehydrogenase activity was noted in mutations at the homologous residues in other acylCoA dehydrogenases, Smelt et al. (6) speculated that $\mathrm{R} 450 \mathrm{H}$ carried some residual activity. We have clearly demonstrated that $\mathrm{R} 450 \mathrm{H}$ mutation is a temperature-sensitive mild mutation.

A416T is a novel mutation and was also revealed to be a temperature-sensitive milder mutation than $\mathrm{R} 450 \mathrm{H}$. A416T is located in a nonconserved residue among seven acyl-CoA dehydrogenases (12). Our expression analysis clearly showed that this A416T mutation retains a significant residual C16-DH 
activity even at $37^{\circ} \mathrm{C}$ and that this activity increased in expression at $30^{\circ} \mathrm{C}$. Together with immunoblot data, we calculated the specific activity of A416T mutant protein to be $20 \%$ of the normal. Cotransfection of A416T and R450H mutant cDNAs did not show interallelic complementation or a dominant negative effect.

VLCAD protein is abundant in heart and skeletal muscle as well as in the liver in human (12). The main clinical symptoms in VLCAD deficiency involve these organs, especially in the severe or milder childhood forms. Hypoketotic hypoglycemia and hypoketotic dicarboxylic aciduria are phenotypes of liver $\beta$-oxidation insufficiency. Cardiomyopathy and rhabdomyolysis are phenotypes of heart and skeletal muscle insufficiencies, respectively. Our report suggests that at least 5 to $10 \%$ residual VLCAD activity may be adequate to avoid hypertrophic cardiomyopathy or a hypoglycemic crisis in childhood but may be not sufficient for energy demands of skeletal muscle after late childhood, and the episodic, isolated myopathic form may occur. As one cannot reach a definitive conclusion based on only one case, a similar analysis in other patients with the myopathic form is needed to confirm this hypothesis.

Finally, it should be noted that the urinary organic acid profile was not significant even when our patient had myalgic attacks with elevated CK. Hypoketotic dicarboxylic aciduria was only detected after a 36-h fast. Ogilvie et al. (4) also reported that no dicarboxylic aciduria was detected after a 24-h fast in an adult form patient whereas the serum CK was elevated to $15,000 \mathrm{U} / \mathrm{L}$. Smelt et al. (6) also reported that organic acid levels in urine were normal both during and between attacks in another patient with the adult form. This means that urinary organic acid analysis is not pertinent for the diagnosis of the mild form of VLCAD deficiency, even during rhabdomyolysis attacks. On the other hand, $\mathrm{C}_{14: 1}$ carnitine was evident under even good clinical conditions in our patient as well as in patients with the adult form. Acylcarnitine analysis should be considered for patients with rhabdomyolysis.

Acknowledgments. The authors thank N. Terada (Department of Pediatrics, Kyoto Prefectural University of Medicine) for acylcarnitine analysis, J. Miyazaki (University of Tokyo) for providing the pCAGGS vector, and M. Ohara for comments on the manuscript.

\section{REFERENCES}

1. Izai K, Uchida Y, Orii T, Yamamoto S, Hashimoto T 1992 Novel fatty acid $\beta$-oxidation enzymes in rat liver mitochondria. I. Purification and properties of very-long-chain acyl-coenzyme A dehydrogenase. J Biol Chem 267:1027-1033
2. Uchida Y, Izai K, Orii T, Hashimoto T 1992 Novel fatty acid $\beta$-oxidation enzymes in rat liver mitochondria. II. Purification and properties of enoyl-coenzyme A (CoA) hydratase/3-hydroxyacyl-CoA dehydrogenase/3-ketoacyl-CoA thiolase trifunctional protein. J Biol Chem 267:1034-1041

3. Vianey-Saban C, Divry P, Brivet M, Nada M, Zabot M-T, Mathieu M, Roe C 1998 Mitochondrial very-long-chain acyl-coenzyme A dehydrogenase deficiency: clinical characteristics and diagnostic consideration in 30 patients. Clin Chim Acta 269:43-62

4. Ogilvie I, Pourfarzam M, Jackson S, Stockdale C, Bartlett K, Turnbull DM 1994 Very-long chain acyl-coenzyme A dehydrogenase deficiency presenting with exercise-induced myoglobinuria. Neurology 44:467-473

5. Straussberg R, Elpeleg ON, Shamir R, Amir J 1998 Recurrent myoglobinuria as a presenting manifestation of very long chain acyl coenzyme A dehydrogenase deficiency. Pediatrics 99:894-895

6. Smelt AHM, Poorthuis BJHM, Onkenhout W, Scholte HR, Andresen BS, van Duinen SG, Gregersen N, Wintzen AR 1998 Very long chain acyl-coenzyme A dehydrogenase deficiency with adult onset. Ann Neurol 43:540-544

7. Minetti C, Garavaglia B, Bado M, Invernizzi F, Bruno C, Rimoldi M, Pons R, Taroni F, Cordone G1998 Very-long-chain acyl-Coenzyme A dehydrogenase deficiency in a child with recurrent myoglobinuria. Neuromuscul Disord 8:3-6

8. Andresen BS, Olpin S, Poorthuis BJ, Scholte HR, Vianey-Saban C, Wanders RJA, Ijlist L, Morris A, Pourfarzam M, Bartlett K, Baumgartner ER, deKlerk JB, Schroeder LD, Corydon TJ, Lund H, Winter V, Bross P, Bolund L, Gregersen N 1998 Clear correlation of genotype with disease phenotype in very-long-chain acyl-CoA dehydrogenase deficiency. Am J Hum Genet 64:479-494

9. Aoyama T, Souri M, Ueno I, Kamijo T, Yamaguchi S, Rhead WJ, Tanaka K, Hashimoto T 1995 Cloning of human very-long-chain acyl-coenzyme A dehydrogenase and molecular characterization of its deficiency in two patients. Am J Hum Genet 57:273-283

10. Strauss AW, Powell CK, Hale DE, Anderson MM, Ahuja A, Brackett JC, Sims HF 1995 Molecular basis of human mitochondrial very-long-chain acyl-CoA dehydrogenase deficiency causing cardiomyopathy and sudden death in childhood. Proc Natl Acad Sci USA 92:10496-10500

11. Orii KO, Aoyama T, Souri M, Orii KE, Kondo N, Orii T, Hashimoto T 1995 Genomic DNA organization of human mitochondrial very-long-chain acyl-CoA dehydrogenase and mutation analysis. Biochem Biophys Res Commun 217:987-992

12. Andresen BS, Bross P, Vianey-Saban C, Divry P, Zabot M-T, Roe CR, Nada MA, Byskov A, Kruse TA, Neve S, Kristiansen K, Knudsen I, Corydon MJ, Gregersen N 1996 Cloning and characterization of human very-long-chain acyl-CoA dehydrogenase cDNA, chromosomal assignment of the gene and identification in four patients of nine different mutations within the VLCAD gene. Hum Mol Genet 5:461-472

13. Souri M, Aoyama T, Orii K, Yamaguchi S, Hashimoto T 1996 Mutation analysis of very-long-chain acyl-coenzyme A dehydrogenase (VLCAD) deficiency: identification and characterization of mutant VLCAD cDNAs from four patients. Am J Hum Genet 58:97-106

14. Cox GF, Souri M, Aoyama T, Rockenmacher S, Varvogli L, Rohr F, Hashimoto T, Korson MS 1998 Reversal of severe hypertrophic cardiomyopathy and excellent neuropsychological outcome in very-long-chain acyl-coenzyme A dehydrogenase deficiency. J Pediatr 133:247-253

15. Verity MA, Turnbull DM 1993 Assay of acyl-CoA dehydrogenase activity in frozen muscle biopsies: application to medium-chain acyl-CoA dehydrogenase deficiency. Biochem Med Metab Biol 49:351-362

16. Aoyama T, Souri M, Ushikubo S, Kamijo T, Yamaguchi S, Kelley RI, Rhead WJ, Uetake K, Tanaka K, Hashimoto T 1995 Purification of human very-long-chain acyl-coenzyme A dehydrogenase and characterization of its deficiency in seven patients. J Clin Invest 95:2465-2473

17. Song X-Q, Fukao T, Yamaguchi S, Miyazawa S, Hashimoto T, Orii T 1994 Molecular cloning and nucleotide sequence of complementary DNA for human hepatic cytosolic acetoacetyl-coenzyme A thiolase. Biochem Biophys Res Commun 198:632-636

18. Watanabe H, Orii KE, Fukao T, Song X-Q, Aoyama T, Ijlst L, Ruiter J, Wanders RJA, Kondo N 2000 Molecular basis of very long chain acyl-CoA dehydrogenase deficiency in three Israeli patients: identification of a complex mutant allele with P65L and K247Q mutations, the former being an exonic mutation causing exon 3 skipping. Hum Mutat 15:430-438

19. Niwa H, Yamamura K, Miyazaki J 1991 Efficient selection for high-expression transfectants with a novel eukaryotic vector. Gene 108:193-200

20. Merinero B, Pascual Pascual SI, Perez-Cerda C, Gangoiti J, Castro M, Gracia MJ, Pascual Castroviejo I, Vianey-Saban C, Andresen B, Gregersen N, Ugarte M 1999 Adolescent myopathic presentation in two sisters with very long-chain acyl-CoA dehydrogenase. J Inher Metab Dis 22:802-810 